\title{
Metabolic Equivalent of Task
}

National Cancer Institute

\section{Source}

National Cancer Institute. Metabolic Equivalent of Task. NCI Thesaurus. Code C89729.

A mathematic formula used to estimate individual oxyg en consumption, and thus energy expenditure, at rest and for various physical activities. 